\section{What is already known on this topic}

Results from studies in monkeys suggest that high daily doses of caffeine in pregnancy increase the risk of stillbirth, but evidence from studies in humans has been lacking

\section{What this study adds}

Pregnant women who drank eight or more cups of coffee a day had more than twice the risk of stillbirth compared with women who did not drink coffee during pregnancy

the timing of the data collection, our information could not be biased by the women's knowledge about the outcome of pregnancy. Potential misclassification is likely to be non-differential, and our results may thus underestimate the true association between coffee drinking and stillbirth. Due to a higher intake of coffee and a faster metabolism among smokers ${ }^{15} 16$ we hypothesised that the fetotoxic effect of caffeine could depend on smoking habits during pregnancy. However, the risk of stillbirth associated with coffee was similar in smokers and non-smokers.

There did not seem to be one single cause that could explain the increased risk of stillbirth among women with a high intake of coffee (see bmj.com).

Information on coffee intake during pregnancy was missing in a quarter of the population. Women with missing information had a different risk profile than women with valid information. However, we have no reason to believe that the association between coffee and stillbirth among women with non-valid information would be different from the one we found.

We thank Morten Frydenberg, associate professor, for statistical advice.
Contributors: See bmj.com

Funding: Danish Research Counsels, Maria Dorthea and Holger From, Haderlev's Foundation, Novo Nordisk Foundation, Danish Research Foundation.

Competing interests: None declared.

Fernandes O, Sabharwal M, Smiley T, Pastuszak A, Koren G, Einarson T. Moderate to heavy caffeine consumption during pregnancy and relationship to spontaneous abortion and abnormal fetal growth: a ship to spontaneous abortion and ab
meta-analysis. Reprod Toxicol 1998;12:435-44.

2 Cnattingius S, Signorello LB, Anneren G, Clausson B, Ekbom A, Ljunger $\mathrm{E}$, et al. Caffeine intake and the risk of first-trimester spontaneous abortion. N Engl J Med 2000; 343:1839-45.

3 Fortier I, Marcoux S, Beaulac-Baillargeon L. Relation of caffeine intake during pregnancy to intrauterine growth retardation and preterm birth. Am J Epidemiol 1993;137:931-40.

4 Golding J. Reproduction and caffeine consumption-a literature review. Early Hum Dev 1995;43:1-14.

5 Gilbert SG, Rice DC, Reuhl KR, Stavric B. Adverse pregnancy outcome in the monkey (Macaca fascicularis) after chronic caffeine exposure. J Phar macol Exp Ther 1988;245:1048-53.

6 Weathersbee PS, Lodge JR. Caffeine: its direct and indirect influence on reproduction. J Reprod Med 1977; 19:55-63.

7 Kirkinen P, Jouppila P, Koivula A, Vuori J, Puukka M. The effect of caffeine on placental and fetal blood flow in human pregnancy. Am J Obstet Gynecol 1983;147:939-49.

8 Resch BA, Papp JG. Effects of caffeine on the fetal heart. Am J Obstet Gynecol 1983;146:231-2

9 Watkinson B, Fried PA. Maternal caffeine use before, during and after pregnancy and effects upon offspring. Neurobehav Toxicol Teratol 1985;7:9-17.

10 Wisborg K, Kesmodel U, Henriksen TB, Olsen SF, Secher NJ. Exposure to tobacco smoke in utero and the risk of stillbirth and death in the first year of life. Am J Epidemiol 2001;154:322-7.

11 Kristensen J, Langhoff-Roos J, Skovgaard LT, Kristensen FB. Validation of the Danish birth registration. J Clin Epidemiol 1996;49:893-7.

12 Knudsen LB, Borlum Kristensen F. Monitoring perinatal mortality and perinatal care with a national register: content and usage of the Danish medical birth register. Community Med 1986:8:29-36.

13 Juel K, Helweg-Larsen K. The Danish registers of causes of death. Dan Med Bull 1999:46:354-7.

14 Bunker ML, McWilliams M. Caffeine content of common beverages. J Am Diet Assoc 1979;74:28-32.

15 Cook DG, Peacock JL, Feyerabend C, Carey IM, Jarvis MJ, Anderson HR, et al. Relation of caffeine intake and blood caffeine concentrations during pregnancy to fetal growth: prospective population based study. $B M J$ 1996;313:1358-62.

16 Dominguez-Rojas V, de Juanes-Pardo JR, Astasio-Arbiza P, OrtegaMolina P, Gordillo-Florencio E. Spontaneous abortion in a hospital population: are tobacco and coffee intake risk factors? Eur J Epidemiol 1994;10:665-8.

(Accepted 5 December 2002)

\title{
Longitudinal study of childhood wheezy bronchitis and asthma: outcome at age 42
}

\author{
Elisabeth Horak, Anna Lanigan, Mary Roberts, Liam Welsh, John Wilson, John B Carlin, \\ Anthony Olinsky, Colin F Robertson
}

Department of Respiratory

Medicine, Royal

Children's Hospital,

Parkville 3052,

Australia

Elisabeth Horak

research fellow

Anna Lanigan

research assistant

Mary Roberts

research assistant

Liam Welsh

research assistant

Anthony Olinsky

director

Colin F Robertson

associate professor

continued over

BMJ 2003;326:422-3
Longitudinal studies have reported that asthma in childhood has a good prognosis. However, most of these studies have not taken into account the severity of childhood symptoms. ${ }^{1}$ The Melbourne Epidemiological Study of Childhood Asthma recruited children at age 7 years and followed them up through adolescence to adulthood. ${ }^{2-5}$ This report describes outcome at age 42 years in relation to symptoms in childhood.

\section{Participants, methods, and results}

In 1964, 401 children (295 with asthma and 106 controls) were randomly selected from a total of 300007 year olds living in metropolitan Melbourne. A further 83 children with severe asthma were included from the same cohort in 1967, at age $10 .{ }^{23}$ Original data were available for 479 participants.
At recruitment, 105 children were classified as controls (children who had never wheezed); 74 had mild wheezy bronchitis $(<5$ episodes of wheezing associated with respiratory tract infection); 104 had wheezy bronchitis ( $\geqslant 5$ episodes of wheezing associated with respiratory tract infection); 113 had asthma (wheezing unassociated with respiratory tract infection); and 83 had severe asthma (onset of asthma symptoms before 3 years of age, persistent symptoms at age of 10, and barrel chest deformity or ratio of forced expiratory volume in one second to forced vital capacity $\leqslant 50 \%$ ).

At each review from the age of 21, participants were classified as follows: no recent asthma (no wheeze in past three years); infrequent asthma (wheezing in past three years but none in past three months); frequent asthma (wheezing in past three months, but less than once a week); or persistent asthma (wheezing in past three months, more than once a week). 
Distribution of asthma and lung function in participants aged 42 according to severity of asthma at age 7 or 10

\begin{tabular}{|c|c|c|c|c|c|c|c|c|}
\hline \multirow[b]{2}{*}{ Symptoms age 7} & \multicolumn{5}{|c|}{ No (\%) at age 42} & \multicolumn{3}{|c|}{ Lung function at age 42} \\
\hline & $\begin{array}{c}\text { No recent } \\
\text { asthma }(n=199)\end{array}$ & $\begin{array}{c}\text { Infrequent } \\
\text { asthma }(n=58)\end{array}$ & $\begin{array}{l}\text { Frequent asthma } \\
\qquad(\mathrm{n}=76)\end{array}$ & $\begin{array}{c}\text { Persistent } \\
\text { asthma }(n=70)\end{array}$ & $\begin{array}{c}\text { Total } \\
(\mathrm{n}=403)\end{array}$ & $\begin{array}{c}\text { No measured } \\
(n=267)\end{array}$ & $\begin{array}{l}\mathrm{FEV}_{1} / \mathrm{FVC} \\
(95 \% \mathrm{Cl})\end{array}$ & $\begin{array}{c}\text { Mean \% of } \\
\text { predicted } \mathrm{FEV}_{1} \\
(95 \% \mathrm{Cl})\end{array}$ \\
\hline Mild wheezy bronchitis & $40(66)$ & $12(20)$ & $9(15)$ & 0 & 61 & 40 & 80 (79 to 82 ) & 109 (103 to 114) \\
\hline Wheezy bronchitis & $50(57)$ & $13(15)$ & $16(18)$ & $9(10)$ & 88 & 62 & 79 (76 to 81$)$ & 102 (98 to 106) \\
\hline Asthma & $28(29)$ & $19(19)$ & $27(28)$ & $24(24)$ & 98 & 70 & $75^{\star}$ (73 to 77 ) & $95^{*}$ (92 to 99$)$ \\
\hline Severe asthma & $8(11)$ & $9(13)$ & $20(29)$ & $33(47)$ & 70 & 42 & $70^{\star}$ (67 to 74$)$ & $85^{*}$ (78 to 91$)$ \\
\hline Control & $73(85)$ & $5(6)$ & $4(5)$ & $4(5)$ & 86 & 53 & 80 (78 to 82$)$ & 104 (101 to 108) \\
\hline
\end{tabular}

$\mathrm{FEV}_{1}=$ forced expiratory volume in 1 second; $\mathrm{FVC}=$ forced vital capacity.

${ }^{*} \mathrm{P}<0.001$ compared with controls

Fifteen of the original cohort had died at follow up, one from asthma. Of the remaining 464, 403 participated in the current review, giving a continuing participation rate of $87 \%$. In all, 267 participants attended the laboratory for measurement of lung function. We calculated mean values of lung function using standard two sample $t$ tests and confidence intervals of the mean by standard methods.

The table shows the clinical expression of asthma at age 42 according to severity of disease at recruitment. The distribution of severity at age 42 has not changed from that at age $35 .{ }^{5}$ The proportion of cases with no recent asthma has increased steadily from $20 \%$ at age 14 years to $40 \%(126 / 317)$ at age 42 .

Lung function was similar to that of controls in participants who had had wheezy bronchitis in childhood (table). Participants who had had asthma aged 7 had reduced lung function at age 42 .

\section{Comment}

Our study shows that the pattern of asthma during childhood predicts outcome. Most children with persistent asthma had continuing symptoms into adult life and reduced lung function. However, children who had intermittent symptoms associated with respiratory tract infections generally had complete resolution of symptoms in adult life. The small number of participants who still had mild, intermittent symptoms at age 42 had normal lung function. This good outcome was achieved despite the fact that anti-inflammatory treatments were not available for most of their childhood.

Contributors: CFR, AO, and JW initiated the project and, together with $\mathrm{EH}, \mathrm{AL}, \mathrm{MR}$ and $\mathrm{LW}$, developed the protocol. EH, AL, MR, and LW were responsible for recruitment, data collection, and data analysis. JBC was the statistician. The manuscript was jointly written and reviewed by all of the authors. CFR is the guarantor.

Funding: National Health and Medical Research Council of Australia. EH was funded by Nationalbank, Austria.

Competing interests: None declared.

1 Ahmed IH, Samet JM. The natural history of asthma. In: Murphy S, Kelly HW, eds. Pediatric asthma. Vol 126. New York: Marcel Dekker, 1999:41-69.

2 Williams HE, McNichol KN. Prevalence, natural history and relationship of wheezy bronchitis and asthma in children: an epidemiological study. BMJ 1969;iv:321-5.

3 McNichol KN, Williams HB. Spectrum of asthma in children. I. Clinical and physiological components. BMJ 1973;iv:7-11.

Kelly WJ, Hudson I, Phelan PD, Pain MC, Olinsky A. Childhood asthma in adult life: a further study at 28 years of age. BMJ 1987;294:1059-62.

5 Oswald H, Phelan PD, Lanigan A, Hibbert M, Bowes G, Olinsky A. Outcome of childhood asthma in mid-adult life. BMJ 1994;309:95-6.

(Accepted 7 November 2002)

\title{
Spontaneous loss of early pregnancy and risk of ischaemic heart disease in later life: retrospective cohort study
}

\author{
Gordon C S Smith, Jill P Pell, David Walsh
}

We recently showed that complications in late pregnancy are associated with an increased risk of maternal ischaemic heart disease (IHD) in later life. ${ }^{1}$ We hypothesised that this may reflect common determinants, such as thrombophilic genetic defects and anticardiolipin antibodies. Spontaneous losses of pregnancy are also associated with inherited and acquired thrombophilias in the mother. ${ }^{2}$ We examined whether spontaneous losses of early pregnancy are associated with maternal risk of IHD.

\section{Participants, methods, and results}

We used routine national maternity data (SMR2) to identify all 129290 eligible women who delivered their first liveborn infant in Scotland during 1981-5. The exclusion and inclusion criteria, definitions, and demographic characteristics were as previously described. ${ }^{1}$ We used national death (GRO) and discharge (SMR1) data to determine the risk of death or hospital admission due to IHD during 1981-99. The cumulative probabilities of survival free from IHD events were assessed with Cox's proportional hazards models with age as the time scale (Stata version 7.0, StataCorp, College Station, TX,USA).

A history of any spontaneous loss of early pregnancy before the first live birth was associated with an increased risk of IHD (table). The association was independent of maternal age at the time of first birth, height, socioeconomic deprivation, essential hypertension, and complications during the first pregnancy. The magnitude of the risk increased with the number of previous losses. By contrast, there was no association between therapeutic abortion and subsequent risk of IHD (adjusted hazard ratio $0.93,95 \%$ confidence interval 0.59 to 1.46 ). Only $0.1 \%$ (162) of women had had a hernia repair, and there was no significant association

\section{Clinical}

Epidemiology and Biostatistics Unit, Murdoch Childrens Research Institute, Parkville 3052, Australia

John B Carlin deputy director

Department of Respiratory Medicine, Alfred Hospital, Melbourne,

Australia

John Wilson associate professor Correspondence to: C F Robertson colin.robertson@ rch.org.au
Department of Obstetrics and Gynaecology, Cambridge University, Box 223

The Rosie Hospital,

Cambridge

CB2 2QQ

Gordon C S Smith professor

Department of Public Health, Greater Glasgow Health Board, Dalian House,

Glasgow G3 8YU

Jill P Pell consultant Information and Statistics Division, Common Services Agency, Edinburgh EH5 3SE

David Walsh statistician

Correspondence to: G C S Smith gcss2@cam.ac.uk

BMJ 2003;326:423-4 